\title{
Autophagy inhibition enhances the inhibitory effects of ursolic acid on lung cancer cells
}

\author{
MIN WANG ${ }^{1-3}$, HONG YU $^{4}$, RAN WU $^{5}$, ZHEN-YIN CHEN ${ }^{5}$, QIAN HU ${ }^{4}$, \\ YAN-FEI ZHANG ${ }^{1,2}$, SAN-HUI GAO ${ }^{1,2}$ and GUANG-BIAO ZHOU ${ }^{1,2}$
}

\author{
${ }^{1}$ State Key Laboratory of Molecular Oncology, National Cancer Center/National Clinical Research Center for \\ Cancer/Cancer Hospital, Chinese Academy of Medical Sciences and Peking Union Medical College, Beijing 100021; \\ ${ }^{2}$ State Key Laboratory of Membrane Biology, Institute of Zoology, Chinese Academy of Sciences and University of \\ Chinese Academy of Sciences, Beijing 100101; ${ }^{3}$ State Key Laboratory of Esophageal Cancer Prevention and Treatment, \\ Zhengzhou University, Zhengzhou, Henan $450052 ;{ }^{4}$ School of Chinese Materia Medica, Beijing University of \\ Chinese Medicine, Beijing 100029; ${ }^{5}$ Guizhou University School of Medicine, Guiyang, Guizhou 550025, P.R. China
}

Received October 6, 2019; Accepted July 16, 2020

DOI: $10.3892 / \mathrm{ijmm} .2020 .4714$

\begin{abstract}
The aim of the present study was to identify natural compounds that bear significant anti-tumor activity. Thus, the effects of 63 small molecules that were isolated from traditional Chinese medicinal herbs on A549 human non-small cell lung cancer (NSCLC) and MCF-7 breast cancer cells were examined. It was found that ursolic acid (UA), a natural pentacyclic triterpenoid, exerted significant inhibitory effect on these cells. Further experiments revealed that UA inhibited the proliferation of various lung cancer cells, including the NSCLC cells, H460, H1975, A549, H1299 and H520, the human small cell lung cancer (SCLC) cells, H82 and H446, and murine Lewis lung carcinoma (LLC) cells. UA induced the apoptosis and autophagy of NSCLC cells. The inhibition of the mammalian target of rapamycin (mTOR) signaling pathway, but not the activation of the extracellular signal-regulated kinase 1/2 (ERK1/2) signaling pathway contributed to the UA-induced autophagy of NSCLC cells. Moreover, the inhibition of autophagy by chloroquine (CQ) or siRNA for autophagy-related gene 5 (ATG5) enhanced the UA-induced inhibition of cell proliferation and promotion of apoptosis, indicating that UA-induced autophagy is a pro-survival mechanism in NSCLC cells. On the whole, these findings suggest that combination treatment
\end{abstract}

Correspondence to: Professor Guang-Biao Zhou, State Key Laboratory of Molecular Oncology, National Cancer Center/National Clinical Research Center for Cancer/Cancer Hospital, Chinese Academy of Medical Sciences and Peking Union Medical College, 17 Pan-Jia-Yuan-Nan-Li, Chaoyang, Beijing 100021, P.R. China E-mail: gbzhou@cicams.ac.cn

Key words: ursolic acid, autophagy, apoptosis, mammalian target of rapamycin, lung cancer with autophagy inhibitors may be a novel strategy with which enhance the antitumor activity of UA in lung cancer.

\section{Introduction}

Lung cancer is the leading cause of cancer-related mortality, accounting for 1.8 million deaths worldwide in 2018 (1). Over the past 2 decades, the use of targeted therapies and immunotherapies has achieved survival benefits in a proportion of patients (2-4). However, the 5-year overall survival rate of all stages combined non-small lung cancer (NSCLC) and small cell lung cancer (SCLC) is currently $18.6 \%$ (5) and 6\% (6), respectively. Therefore, the development of novel treatment approaches, including rationally designed combination therapies, is urgently required in order to improve the clinical outcomes of patients.

Natural products (NPs) are major sources of new drugs due to their chemical structure diversity (7-9). In 1940 and 2014, the US Food and Drug Administration (FDA) approved 175 anticancer small molecules, of which $63 \%$ were either NPs or directly derived from NPs $(10,11)$. Ursolic acid (UA) is a pentacyclic triterpenoid natural compound initially identified in the epicuticular waxes of apples in the 1920s and is widely distributed in the peel of numerous fruits, as well as in medicinal herbs and other plants $(12,13)$. UA displays a wide range of pharmacological effects, such as anti-inflammatory $(14,15)$, antioxidant (16), antitumor (17,18), cardioprotective (19) and immunomodulatory $(20,21)$ activities. UA has been shown to possess a variety of anticancer capabilities in vitro and in vivo, including the ability to inhibit the proliferation of multiple types of tumor cells, induce apoptosis, induce cell cycle arrest, suppress tumor invasion, metastasis and angiogenesis (22-27). However, the underlying anticancer mechanisms of UA in lung cancer are not yet fully understood.

Autophagy is an evolutionarily conserved process in which intracellular membrane structures undergo dynamic morphological changes that lead to the degradation of cellular proteins and cytoplasmic organelles (28). Autophagy is a 
double-edged sword and can either repress or promote cell apoptosis, depending on the cell type, nutrient supply and stimulus $(29,30)$. Recent studies have revealed that several signaling pathways regulate autophagy, such as the mammalian target of rapamycin (mTOR) pathway and the extracellular signal-regulated kinase $1 / 2$ (ERK1/2) pathway $(28,31,32)$. It has been reported that UA induces autophagy in some types of cancer cells $(33,34)$. However, the underlying mechanisms of UA-induced autophagy are not yet fully understood.

According to the theory of Traditional Chinese Medicine (TCM), lung cancer is the result of 'heat and toxin accumulation' within the body, and medicinal herbs with the 'heat-clearing and detoxification' activity are considered to have anti-lung cancer activity. In the present study, compounds isolated from the 'heat-clearing and detoxification' medicinal herbs were collected and the effects of 63 previously untested compounds (Table SI) on the human NSCLC cell line, A549, were examined. As breast cancer is the most commonly diagnosed type of cancer and the leading cause of cancer-related mortality among women (1), the human breast cancer cell line MCF-7, was also examined. It was reported that UA exhibited potent anticancer activity against these cells. Further experiments revealed that UA suppressed the proliferation, and induced the apoptosis and autophagy of lung cancer cells. It was identified that the inhibition of the mTOR signaling pathway, rather than the activation of the ERK1/2 signaling pathway, was one of the mechanisms responsible for the UA-induced autophagy of NSCLC cells. Of note, the inhibition of autophagy by chloroquine (CQ) or siRNA for autophagy-related gene 5 (ATG5) enhanced the UA-induced inhibition of proliferation and the induction of apoptosis, suggesting that UA-induced autophagy plays a pro-survival role in NSCLC cells. These findings suggest that the combined use of UA and autophagy inhibitors may be a promising therapeutic strategy for lung cancer.

\section{Materials and methods}

Reagents and antibodies. UA and the custom compound library (cat. no. LC00) containing 63 plant-sourced natural products (Table SI) were purchased from Target Molecule Corp.; chloroquine (CQ) and 4,6-diamidino-2-phenylindole (DAPI) were purchased from Sigma-Aldrich Merck KGaA; LY294002 and 3BDO were obtained from MedChemExpress; U0126 was obtained from Cell Signaling Technology, Inc. The cells were treated with $5 \mu \mathrm{M}$ CQ for 25 or $49 \mathrm{~h}$. The cells were treated with $10 \mu \mathrm{M}$ LY294002 or $5 \mu \mathrm{M}$ U0126 for $25 \mathrm{~h}$. The cells were treated with 5 or $10 \mu \mathrm{M} 3 \mathrm{BDO}$ for $25 \mathrm{~h}$. Antibodies used included rabbit anti-microtubule-associated protein 1 light chain 3 (LC3; cat. no. L7543, 1:1,000 for western blot analysis) and mouse anti-actin (cat. no. A5441, 1:5,000 for western blot analysis) from Sigma-Aldrich Merck $\mathrm{KGaA}$; rabbit anti-poly(ADP-ribose) polymerase (PARP; cat. no. 9542, 1:1,000 for western blot analysis), rabbit anti-B-cell lymphoma 2 (Bcl-2; cat. no. 2870, 1:1,000 for western blot analysis), rabbit anti-ATG5 (cat. no. 12994, 1:1,000 for western blot analysis), rabbit anti-S6K (cat. no. 9202, 1:1,000 for western blot analysis), rabbit anti-phospho-S6K (Thr389) (cat. no. 9205, 1:1,000 for western blot analysis), rabbit anti-phospho-S6 ribosomal protein (Ser240/244) (cat. no. 5364, 1:1,000 for western blot analysis), rabbit anti-S6 ribosomal protein (cat. no. 2217, 1:1,000 for western blot analysis), rabbit anti-eukaryotic translation initiation factor 4E-binding protein 1 (4E-BP1; cat. no. 9644, 1:1,000 for western blot analysis), rabbit anti-phospho-4E-BP1 (Ser65) (cat. no. 9451, 1:1,000 for western blot analysis) and rabbit anti-phospho-ERK1/2 (Thr202/Tyr204) (cat. no. 4370, 1:2,000 for western blot analysis) from Cell Signaling Technology, Inc.; rabbit anti-ERK2 (cat. no. ab32081, 1:1,000 for western blot analysis) from Abcam; rabbit anti-phospho-Akt (Ser473) (cat. no. sc-7985-R, 1:500 for western blot analysis) and rabbit anti-Akt (cat. no. sc-8312, 1:500 for western blot analysis) from Santa Cruz Biotechnology, Inc..

Cells and cell culture. The human NSCLC cell lines, H460, H1975 (harboring EGFR-L858R/T790M mutations), A549, H1299 and H520, the human SCLC cell lines, H82 and H446, the human breast cancer cell line, MCF-7, and the C57BL/6 murine Lewis lung carcinoma cell line, LLC, were obtained from the American Type Culture Collection (ATCC). The cells were cultured in DMEM or RPMI-1640 supplemented with $10 \%$ fetal bovine serum (FBS; Gibco, Thermo Fisher Scientific, Inc.) at $37^{\circ} \mathrm{C}$ in a humidified atmosphere containing $5 \% \mathrm{CO}_{2}$.

Cell viability assay. Cell viability was determined by 3-(4,5dimethylthiazol-2-yl)-5-(3-carboxymethoxyphenyl)-2-(4-sulfophenyl)$2 \mathrm{H}$-tetrazolium, inner salt (MTS) assay, according to the protocol of the CellTiter $96^{\circledR} \mathrm{AQ}_{\text {ueous }}$ One Solution Cell Proliferation Assay kit (Promega Corporation). A total of $100 \mu \mathrm{l}$ of cell suspension were seeded onto each well of 96-well plates. The cells were co-incubated with UA for 24 to $72 \mathrm{~h}$, and $20 \mu \mathrm{l}$ of CellTiter $96^{\circledR} \mathrm{AQ}_{\text {ueous }}$ One Solution reagent was added to each well, and the cells were then incubated at $37^{\circ} \mathrm{C}$ for $1-2 \mathrm{~h}$. The absorbance was measured at $490 \mathrm{~nm}$ using a microplate reader (Bio-Tek Instruments, Inc.). The half maximal inhibitory concentration $\left(\mathrm{IC}_{50}\right)$ values were calculated from appropriate dose-response curves.

Colony formation assay. The H460 and H1975 cells were seeded into 6-well plates and cultured in RPMI-1640 supplemented with $10 \% \mathrm{FBS}$ at $37^{\circ} \mathrm{C}$ in a humidified atmosphere containing $5 \% \mathrm{CO}_{2}$ overnight. The cells were then exposed to 10 and $15 \mu \mathrm{M}$ UA for approximately 7 days until the cells grew to visible colonies. The colonies were fixed in methanol and stained with $0.005 \%$ crystal violet (Sigma-Aldrich Merck KGaA) for $30 \mathrm{~min}$ at room temperature. Colonies comprising $>50$ cells were counted using an Olympus inverted phase-contrast microscope (Olympus Corporation).

Apoptosis assay. Cell apoptosis was analyzed using the Annexin V-FITC Apoptosis Detection kit (BD Biosciences) according to the manufacturer's instructions. The cells were treated with the indicated protocols, collected, resuspended in Annexin-V binding buffer, followed by incubation with Annexin V-FITC and propidium iodide (PI) for $15 \mathrm{~min}$ at room temperature in the dark, and were examined by flow cytometry using a FACSCalibur flow cytometer (BD Biosciences).

Western blot analysis. The preparation of whole cell protein lysates and western blot analysis were performed as previously described (35). The membranes were incubated with the 

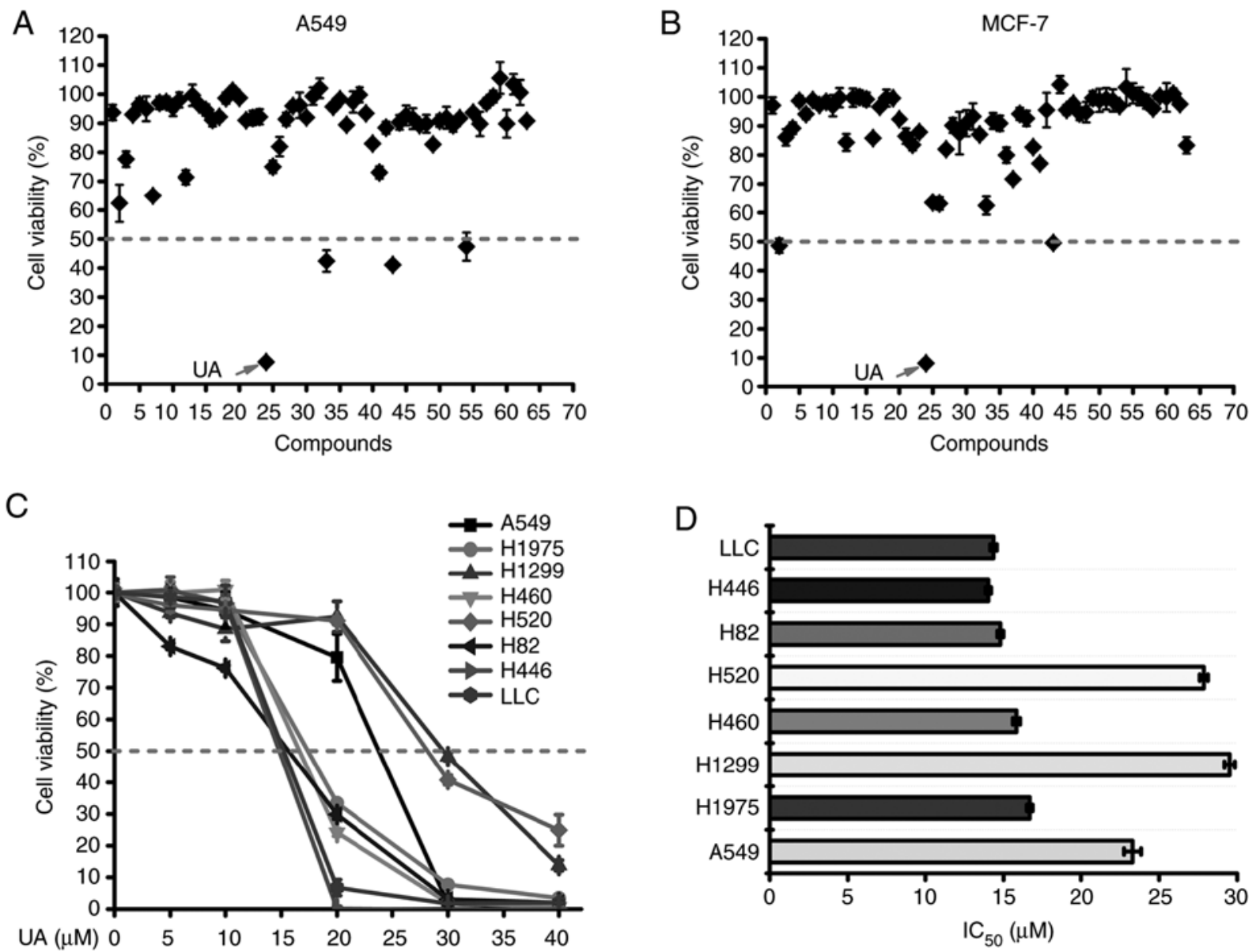

Figure 1. Identification of UA as a potent anticancer compound. (A and B) A549 and MCF-7 cells were treated with 63 natural compounds isolated from traditional Chinese medicinal herbs at $40 \mu \mathrm{M}$ for $48 \mathrm{~h}$. Cell viability was assessed by MTS assay and presented as relative viability normalized to control. (C) A total of 8 lung cancer cell lines were treated with various concentrations of UA for $48 \mathrm{~h}$, cell viability was evaluated by MTS assay and shown as relative viability in comparison with control. (D) $\mathrm{IC}_{50}$ values of $\mathrm{UA}$ for the indicated cell lines are expressed as the means $\pm \mathrm{SD}$. UA, ursolic acid.

indicated primary antibodies at $4^{\circ} \mathrm{C}$ overnight, followed by incubation with the horseradish peroxidase-conjugated anti-mouse (cat. no. 115-035-003, Jackson ImmunoResearch Laboratories, Inc.; 1:10,000) or anti-rabbit (cat. no. 111-035-003, Jackson ImmunoResearch Laboratories, Inc.; 1:10,000) secondary antibodies for $2 \mathrm{~h}$ at room temperature. The densitometric quantification of protein expression was performed using ImageJ software (version 1.4.3.67; National Institutes of Health).

Cell morphological analysis. The H460, H1975 and A549 cells were seeded in 12 -well plates and incubated at $37^{\circ} \mathrm{C}$ in a humidified atmosphere containing $5 \% \mathrm{CO}_{2}$ overnight for cell attachment. The following day, the cells were treated with UA at 10,15 and $20 \mu \mathrm{M}$. Following incubation at $37^{\circ} \mathrm{C}$ in a humidified atmosphere containing $5 \% \mathrm{CO}_{2}$ for $24 \mathrm{~h}$, the morphology of the cells was observed and photographed using an Olympus inverted phase-contrast microscope (Olympus Corporation).

Immunofluorescence assay. The H460 and H1975 cells were seeded on the cover slides with $1 \%$ gelatin in 6 -well plates and cultured in RPMI-1640 supplemented with $10 \% \mathrm{FBS}$ at $37^{\circ} \mathrm{C}$ in a humidified atmosphere containing $5 \% \mathrm{CO}_{2}$ overnight. The cells were then treated with UA at $15 \mu \mathrm{M}$. Following incubation at $37^{\circ} \mathrm{C}$ in a humidified atmosphere containing $5 \% \mathrm{CO}_{2}$ for $16 \mathrm{~h}$, the cells were fixed with $4 \%$ paraformaldehyde for
20 min, washed with $150 \mathrm{mM}$ glycine in PBS, and permeabilized with $0.1 \%$ Triton X-100 in PBS for $15 \mathrm{~min}$ at room temperature. After blocking with 5\% BSA for $1 \mathrm{~h}$ at room temperature, the cells were incubated with LC3 antibody (cat. no. L7543, Sigma-Aldrich Merck KGaA; $1: 100)$ at $4^{\circ} \mathrm{C}$ overnight and then incubated with FITC-conjugated secondary antibody (cat. no. ZF-0311, ZSGB-BIO; 1:100) for $2 \mathrm{~h}$ at room temperature. Nuclei were stained with DAPI for $2 \mathrm{~min}$ at room temperature. Images were acquired using a laser confocal scanning microscope (N-STORM, Nikon Corporation).

Small interfering RNAs (siRNAs) and transfection. The specific target sequences of ATG5 (sense, 5'-GACGUUGGU AACUGACAAATT-3' and antisense, 5'-UUUGUCAGU UACCAACGUCTT-3') (36) and the negative control (sense, 5'-UUCUCCGAACGUGUCACGUTT-3' and antisense, 5'-ACGUGACACGUUCGGAGAATT-3') were synthesized by GenePharma. The cells were transfected with the $50 \mathrm{nM}$ siRNA using Lipofectamine 3000 (Invitrogen; Thermo Fisher Scientific, Inc.) according to the manufacturer's instructions. The H460 and H1975 cells were transfected with the siRNAs for $36 \mathrm{~h}$, and then treated with $0-25 \mu \mathrm{M}$ of UA for 24 or $48 \mathrm{~h}$.

Statistical analysis. The results are presented as the means \pm standard deviation (means \pm SD). A two-tailed 

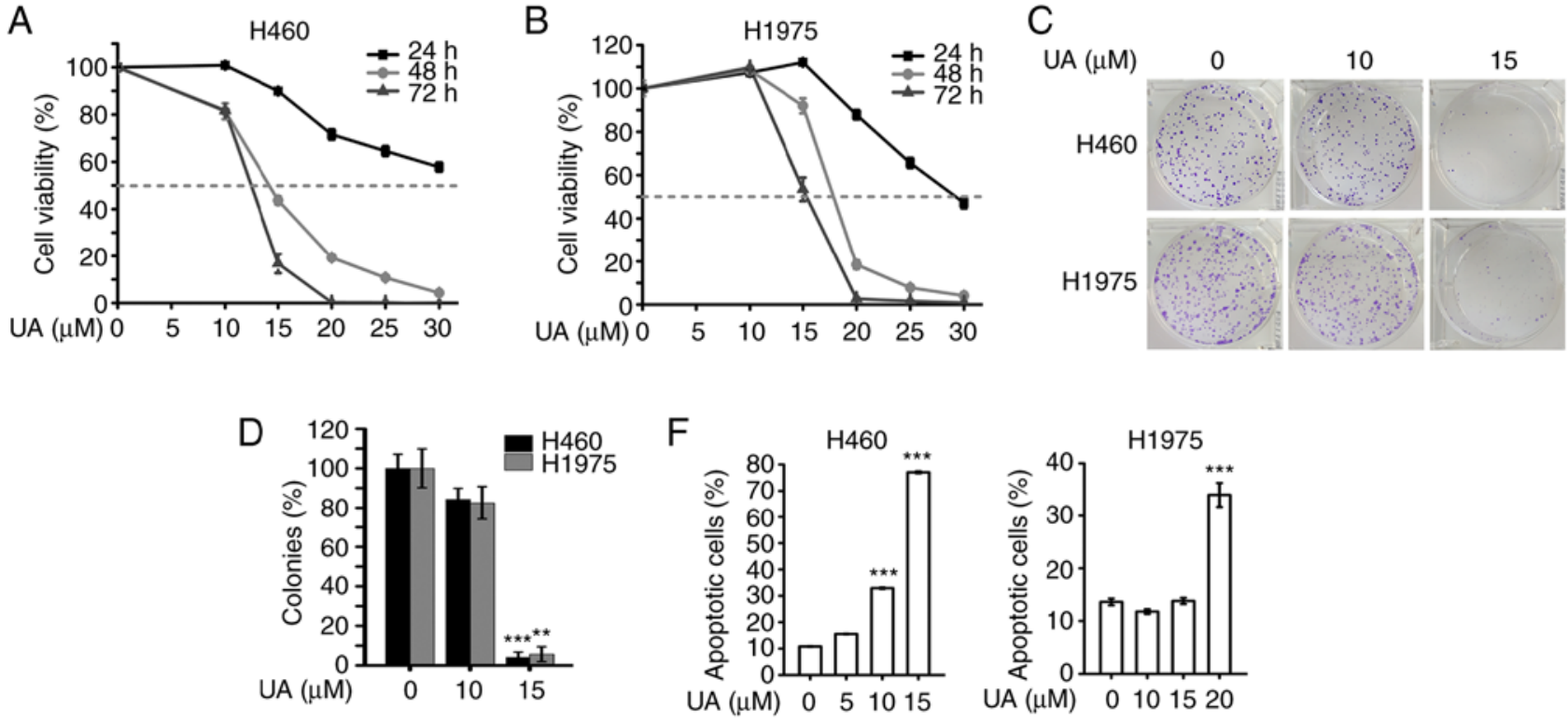

E

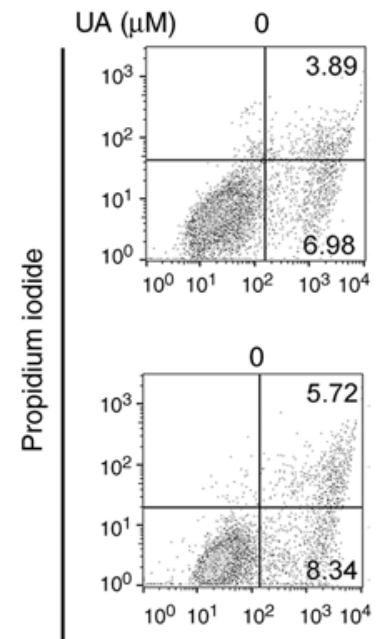

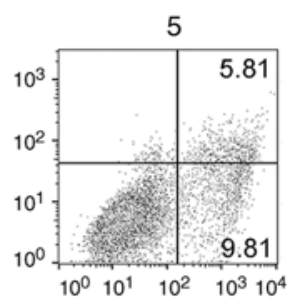
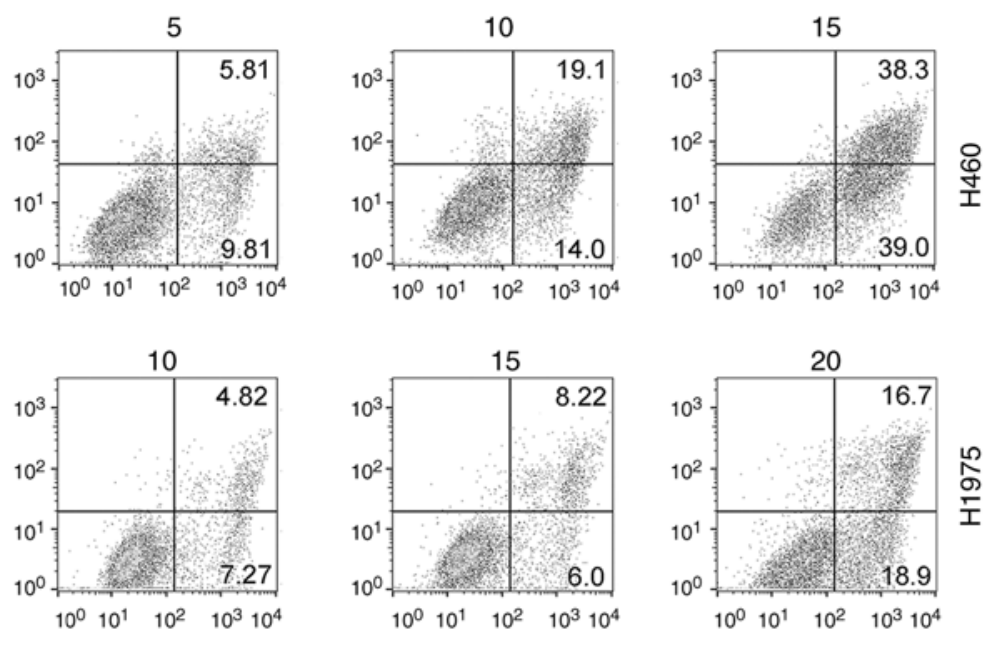

Annexin V-FITC
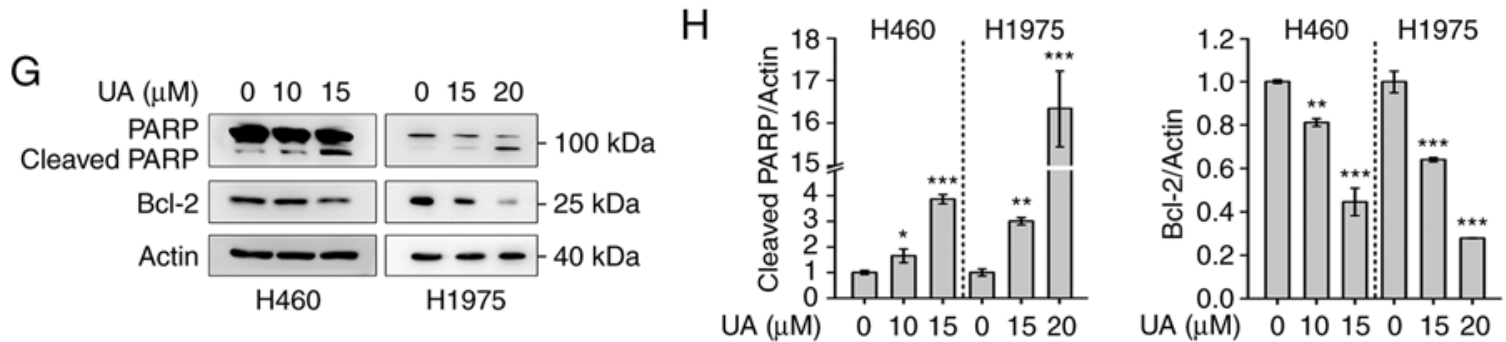

Figure 2. UA inhibits proliferation and induces apoptosis of $\mathrm{H} 460$ and $\mathrm{H} 1975$ cells. (A and B) $\mathrm{H} 460$ and $\mathrm{H} 1975$ cells were treated with the indicated concentrations of UA for the indicated periods of time, and cell viability was determined by MTS assay. (C) Colony formation assay was performed in H460 and H1975 cells with indicated concentrations of UA. Representative images are shown. (D) Quantification of colonies. ${ }^{* *} \mathrm{P}<0.01$ and ${ }^{* * *} \mathrm{P}<0.001$. (E) H460 and H1975 cells were treated with the indicated concentrations of UA for $48 \mathrm{~h}$, and cell apoptosis was analyzed by flow cytometry using Annexin V-FITC/PI staining. Representative images are shown. (F) Quantification of flow cytometric analysis of apoptosis. ${ }^{* * * *} \mathrm{P}<0.001$. (G) H460 and $\mathrm{H} 1975$ cells were treated with the indicated concentrations of UA for $48 \mathrm{~h}$, harvested, and subjected to western blot analysis using the indicated antibodies. Actin was used as a loading control. (H) Relative densitometric quantification of protein expression detected in $(\mathrm{G})$. Data are presented as the means $\pm \mathrm{SD}(\mathrm{n}=3) .{ }^{*} \mathrm{P}<0.05,{ }^{* * *} \mathrm{P}<0.01$ and ${ }^{* * * *} \mathrm{P}<0.001$. UA, ursolic acid.

Student's t-test or one-way ANOVA with Bonferroni's post hoc test was used to determine statistically significant differences. P-values $<0.05$ were considered to indicate statistically significant differences.

\section{Results}

Identification of UA as a potent anticancer compound. Compounds from medicinal herbs usually have moderate 
A

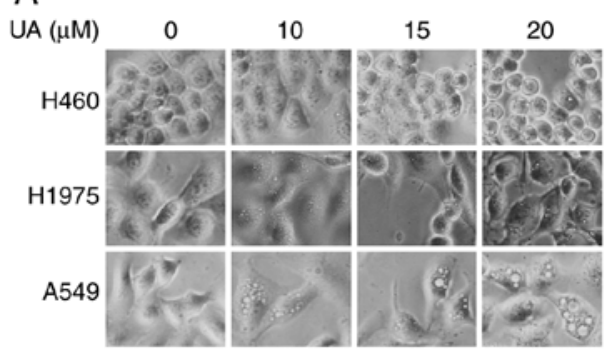

B

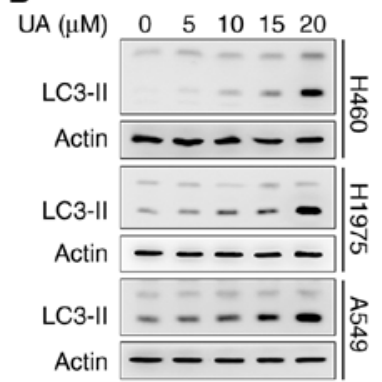

C
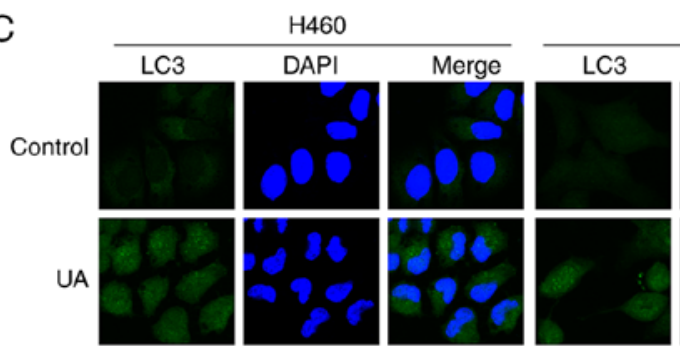

H1975
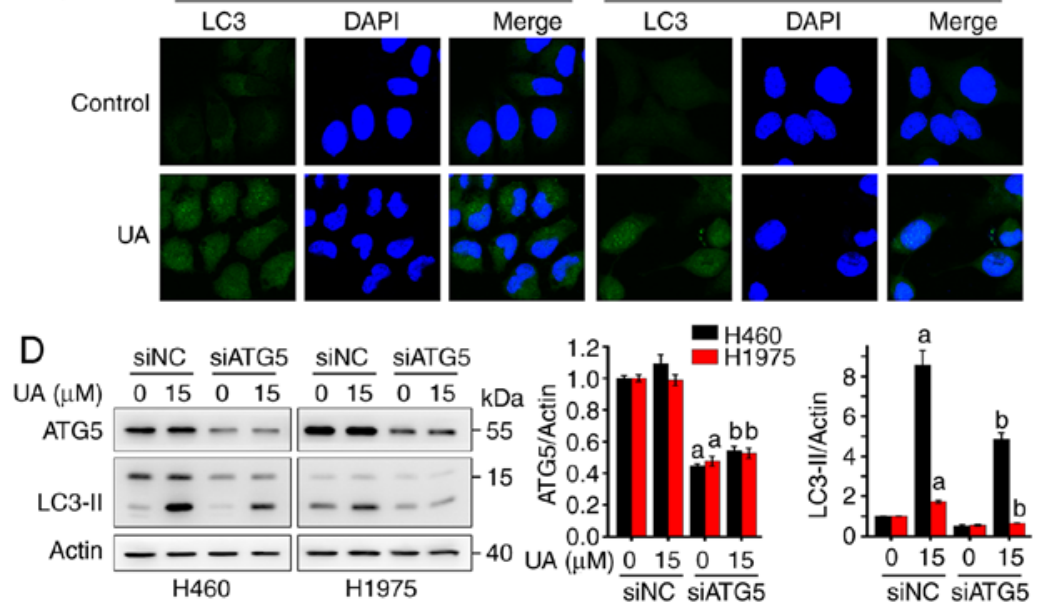

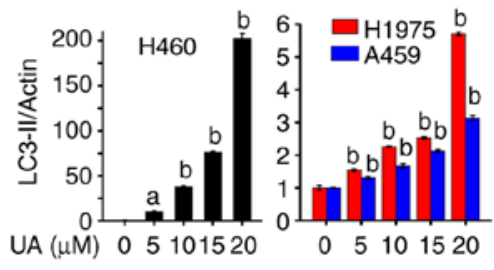

$\mathrm{E} C Q(\mu \mathrm{M}) \quad 0 \quad 0000505$

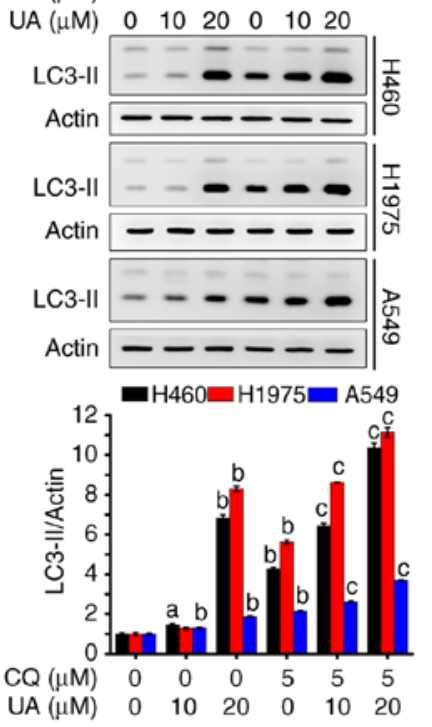

Figure 3. UA induces autophagy and increases the autophagic flux in NSCLC cells. (A) H460, H1975 and A549 cells were treated with UA at 10,15 and $20 \mu \mathrm{M}$ for $24 \mathrm{~h}$, followed by obtaining images under an Olympus inverted phase-contrast microscope. (B) NSCLC cells were treated with the indicated concentrations of UA for $24 \mathrm{~h}$, and the expression levels of LC3 were analyzed by western blot analysis (left panel). Relative densitometric quantification of LC3-II expression was performed using western blot bands and data are presented as the mean $\pm \mathrm{SD}\left(\mathrm{n}=3\right.$; right panel). ${ }^{\mathrm{a}} \mathrm{P}<0.01$ and ${ }^{\mathrm{b}} \mathrm{P}<0.001$. (C) $\mathrm{H} 460$ and $\mathrm{H} 1975$ cells were treated with $15 \mu \mathrm{M}$ UA for $16 \mathrm{~h}$, cells were then analyzed by immunofluorescence assay using LC3 antibody (green) and DAPI (blue). (D) H460 and H1975 cells were transfected with siNC or siATG5 for $36 \mathrm{~h}$, then treated with UA at $15 \mu \mathrm{M}$ for 24 and $48 \mathrm{~h}$ respectively, lysed, and whole cell lysates were subjected to western blot analysis using the indicated antibodies. Relative densitometric quantification of protein expression and data are presented as the means \pm SD (n=3). ${ }^{\mathrm{a}} \mathrm{P}<0.001$ vs. siNC $0 \mu \mathrm{M}$ UA, ${ }^{\mathrm{b}} \mathrm{P}<0.001$ vs. siNC $15 \mu \mathrm{M}$ UA. (E) H460, H1975 and A549 cells were pre-treated without or with $5 \mu \mathrm{M}$ CQ for $1 \mathrm{~h}$, followed by UA treatment at 10 and $20 \mu \mathrm{M}$ for $24 \mathrm{~h}$, and the expression levels of LC3 were examined by western blot analysis. Relative densitometric quantification of the LC3-II expression and data are presented as the means $\pm \mathrm{SD}(\mathrm{n}=3)$. ${ }^{\mathrm{a}} \mathrm{P}<0.01$ vs. vehicle, ${ }^{\mathrm{b}} \mathrm{P}<0.001$ vs. vehicle, ${ }^{\mathrm{c}} \mathrm{P}<0.001$ vs. $5 \mu \mathrm{M} \mathrm{CQ}$. UA, ursolic acid; $\mathrm{CQ}$, chloroquine.

anticancer activity. In the present study, in order to examine the anticancer activity of the compounds, the A549 and MCF-7 cells were treated with the compounds and cell viability was determined by MTS assay. To reach a high efficacy in the identification of candidate compounds, a relatively high concentration $(40 \mu \mathrm{M})$ was used for each molecule in the initial screening. For compounds that exhibited a significant anticancer activity, further experiments using lower concentrations were carried out; for those that did not exhibit a satisfactory activity (inhibition rate $<50 \%$ ), no further experiments were performed. As shown in Fig. 1A and B, UA exhibited the most potent cytotoxicity against these 2 cancer cell lines among the 63 natural compounds tested (Table SI). The inhibitory effect of UA on the proliferation of 8 lung cancer cell lines (5 NSCLC cell lines: A549, H1975, H1299, H460 and H520; and 2 SCLC cell lines: H82, H446; and the murine Lewis lung carcinoma cell line, LLC) was further examined by MTS assay by treating the cells with various concentrations of UA. Treatment with UA $(0-40 \mu \mathrm{M})$ for $48 \mathrm{~h}$ suppressed the proliferation of these 8 lung cancer cell lines in a dose-dependent manner (Fig. 1C). The half maximal inhibitory concentration $\left(\mathrm{IC}_{50}\right)$ values of UA for these 8 cell lines were $23.3 \pm 0.54$,
$16.68 \pm 0.18,29.51 \pm 0.34,15.83 \pm 0.23,27.86 \pm 0.26,14.8 \pm 0.2$, $14.02 \pm 0.17$ and $14.36 \pm 0.21 \mu \mathrm{M}$, respectively (Fig. 1D).

UA inhibits the proliferation and induces the apoptosis of H460 and H1975 cells. By using MTS assay, it was found that UA significantly suppressed the proliferation of the H460 and H1975 cells in a dose- and time-dependent manner (Fig. 2A and B). Furthermore, UA markedly suppressed the colony formation activity of the H460 and H1975 cells, as assessed by colony formation assay (Fig. 2C and D).

To investigate whether UA induces the apoptosis of the cells, the H460 and H1975 cells were treated with UA at the indicated concentrations for $48 \mathrm{~h}$ and apoptosis was detected by Annexin V-FITC/PI double staining and flow cytometric analysis. The upper right and lower right quadrants of the dot plots were counted as apoptotic cells. As shown in Fig. 2E and F, UA markedly increased the percentage of Annexin V (+) apoptotic cells compared with the control group. In addition, the expression of PARP, a well-known cellular substrate of caspases, and that of $\mathrm{Bcl}-2$, the major regulator of the intrinsic (mitochondrial) apoptotic pathway (37), were examined by western blot analysis. As shown in Fig. $2 \mathrm{G}$ and H, treatment of 


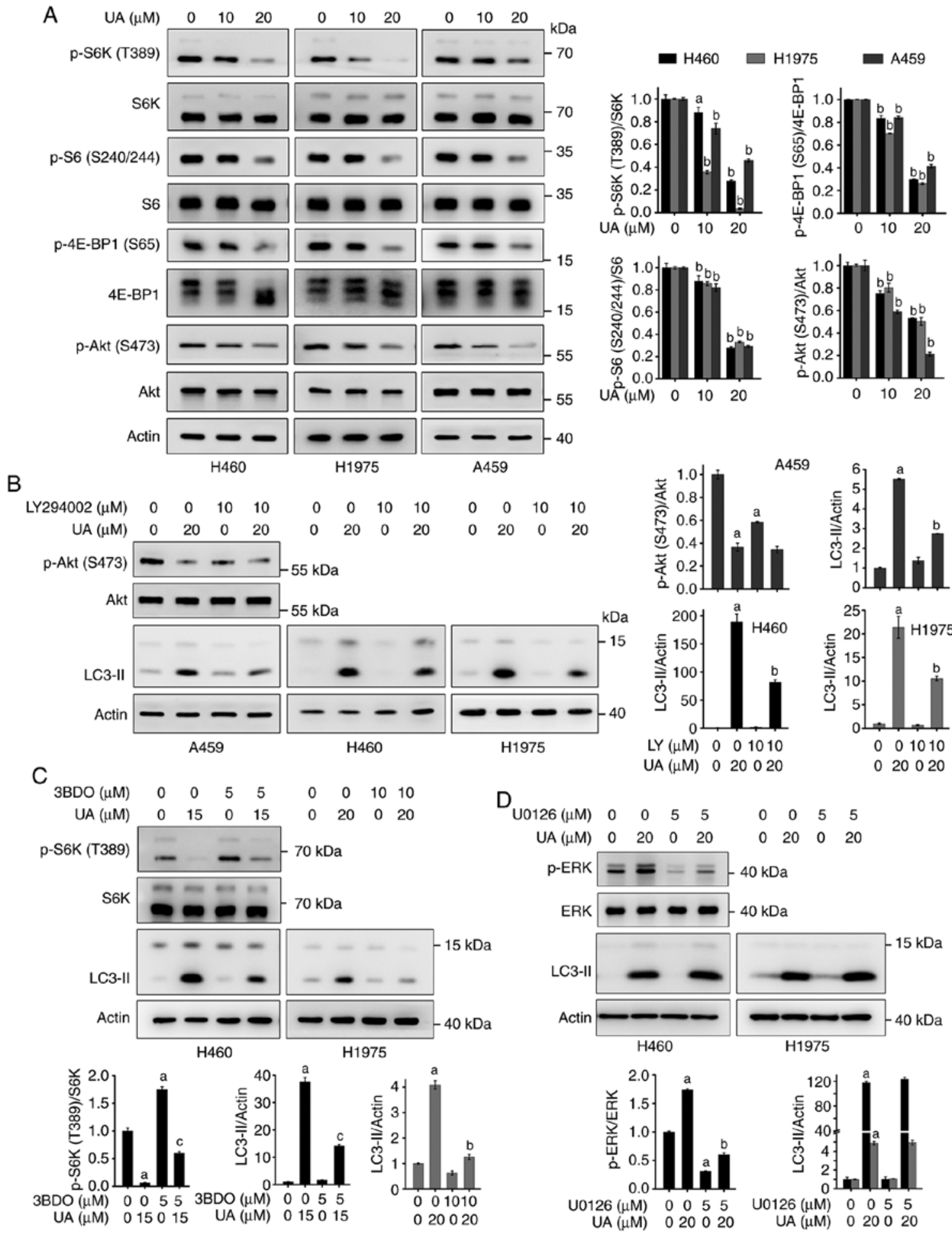

Figure 4. UA-induced autophagy is attributed to the inhibition of the PI3K/Akt/mTOR signaling pathway. (A) NSCLC cells were treated with the indicated concentrations of UA for $24 \mathrm{~h}$, whole cell lysates were subjected to western blot analysis with the indicated antibodies. Actin was used as a loading control (left panels). Relative densitometric quantification of protein expression was performed using the western blot bands and data are presented as the means \pm SD ( $=3$; right panels). ${ }^{\mathrm{a}} \mathrm{P}<0.05$ and ${ }^{\mathrm{b}} \mathrm{P}<0.001$. (B-D) NSCLC cells were pre-treated without or with indicated concentrations of LY294002, 3BDO or U0126 for $1 \mathrm{~h}$, and then incubated with 15 or $20 \mu \mathrm{M}$ UA for $24 \mathrm{~h}$. Whole cell lysates were obtained and subjected to western blot analysis with the indicated antibodies. Relative densitometric quantification of protein expression was performed and data are presented as the means $\pm \mathrm{SD}(\mathrm{n}=3)$. ${ }^{a} \mathrm{P}<0.001 \mathrm{vs}$. vehicle, ${ }^{b} \mathrm{P}<0.001 \mathrm{vs} .20 \mu \mathrm{M}$ UA, ${ }^{~} \mathrm{P}<0.001$ vs. $15 \mu \mathrm{M}$ UA. UA, ursolic acid; LY, LY294002.

the $\mathrm{H} 460$ and $\mathrm{H} 1975$ cells with UA for $48 \mathrm{~h}$ increased the level of cleaved PARP and decreased the expression of Bcl-2.

$U A$ induces autophagy and increases the autophagic flux in NSCLC cells. By observation with an inverted phase-contrast microscopy, it was found that treatment of the H460, H1975 and A549 cells with UA for $24 \mathrm{~h}$ induced vacuoles in the cytoplasm, suggesting that UA regulates autophagy in these cells (Fig. 3A). LC3 is associated with the formation of the autophagosome membrane and usually displays a molecular form conversion 

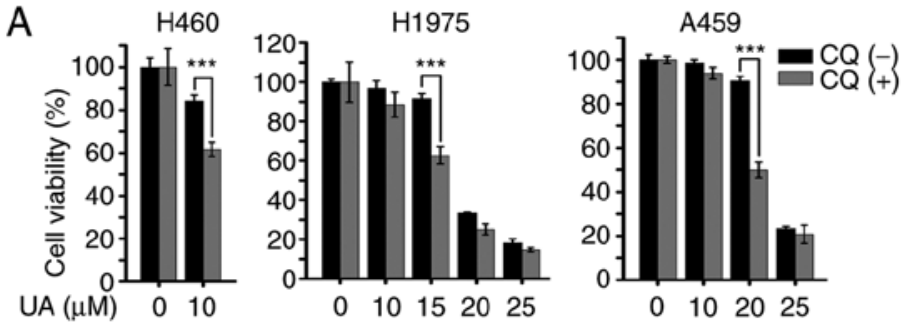

B
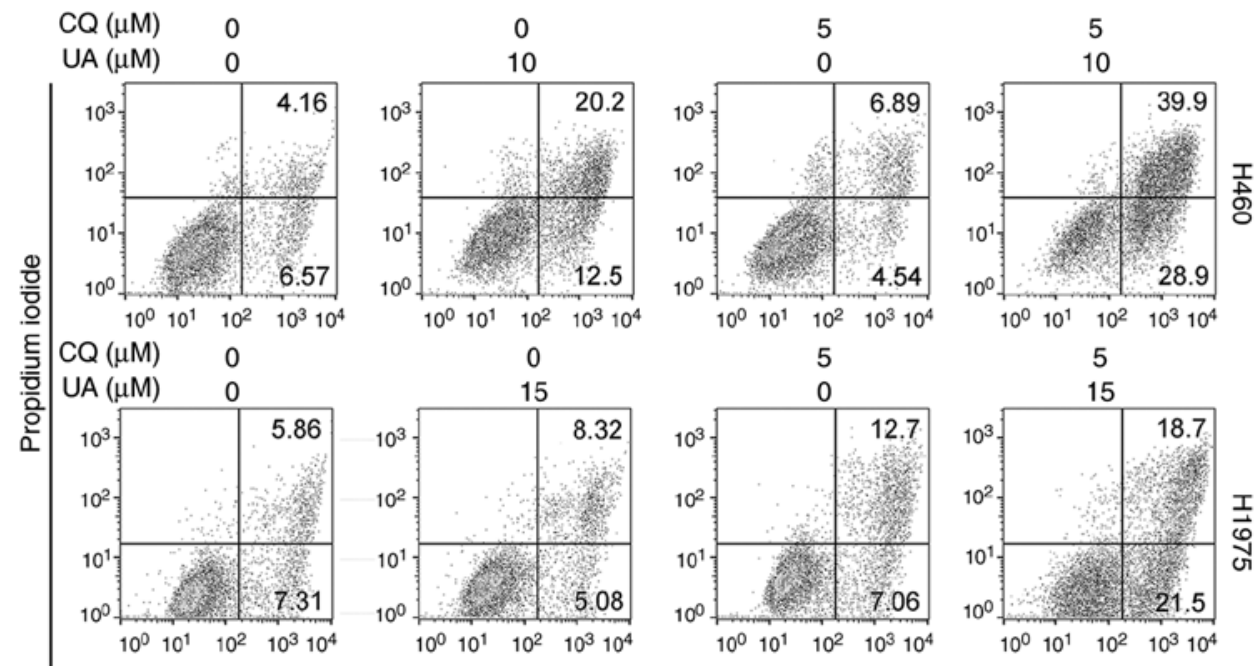

Annexin V-FITC
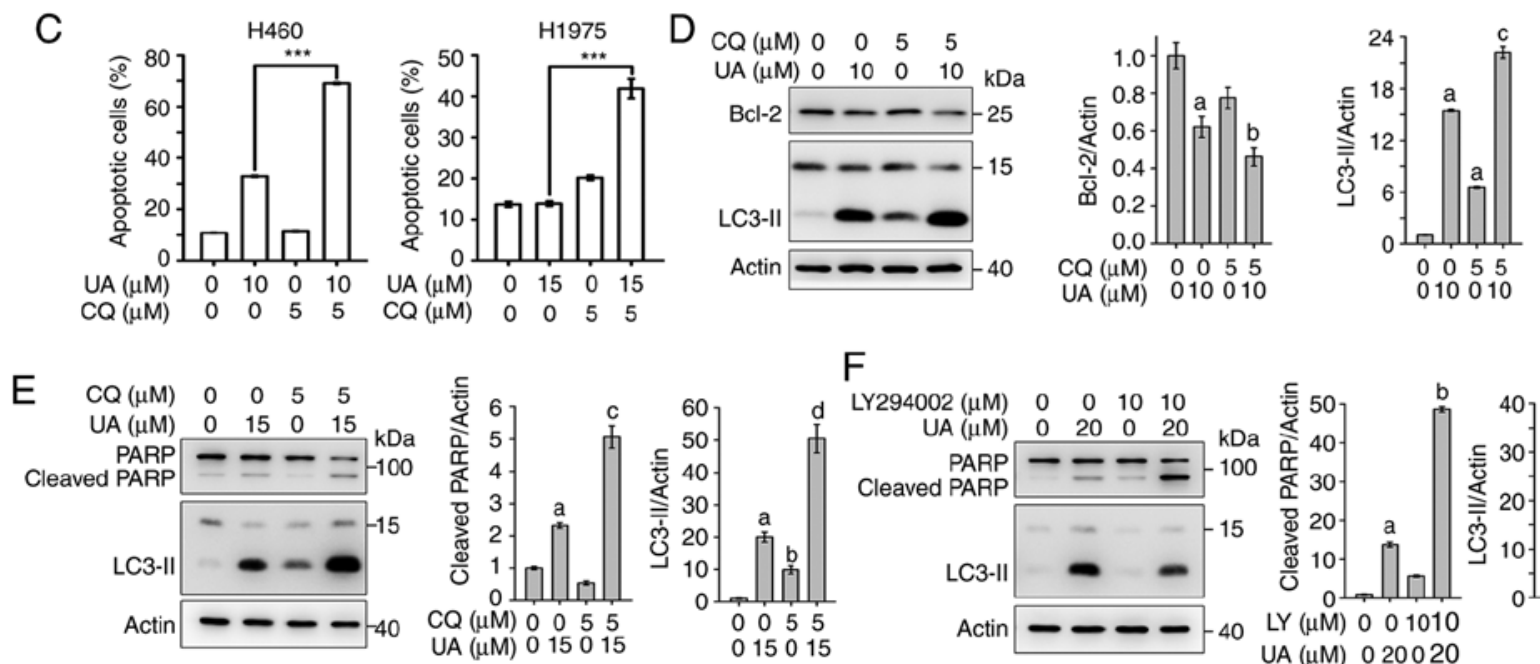

F
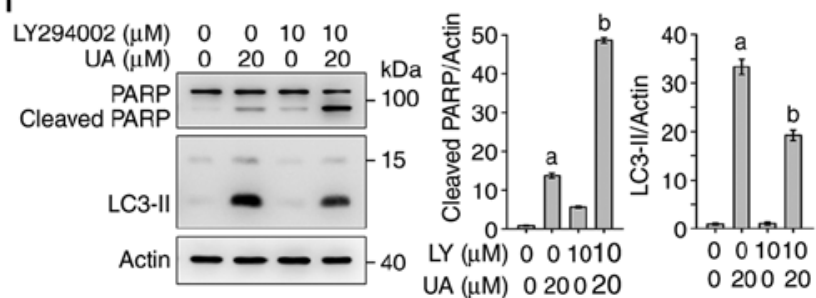

Figure 5. Autophagy inhibition by CQ enhances the UA-induced inhibition of the proliferation and promotes the UA-induced apoptosis of NSCLC cells. (A) NSCLC cells were treated with the indicated concentrations of UA without or with $5 \mu \mathrm{M} \mathrm{CQ}$ for $48 \mathrm{~h}$, cell viability was assessed by MTS assay and data are presented as relative viability to the control. ${ }^{* * *} \mathrm{P}<0.001$. (B) $\mathrm{H} 460$ and $\mathrm{H} 1975$ cells were pre-treated without or with $5 \mu \mathrm{M} \mathrm{CQ}$ for $1 \mathrm{~h}$, followed by treatment with UA at the indicated concentrations for $48 \mathrm{~h}$, cell apoptosis was analyzed by flow cytometry using Annexin V-FITC/PI staining. Representative images are shown. (C) Quantification of flow cytometric analysis of apoptosis. ${ }^{* * *} \mathrm{P}<0.001$. (D) $\mathrm{H} 460$ cells were pre-treated without or with $5 \mu \mathrm{M} \mathrm{CQ}$ for $1 \mathrm{~h}$, then incubated with $10 \mu \mathrm{M} \mathrm{UA}$ for $48 \mathrm{~h}$, lysed, and whole cell lysates were subjected to western blot analysis using the indicated antibodies. Actin was used as a loading control (left panel). Relative densitometric quantification of protein expression was performed and data are presented as the means \pm SD ( $\mathrm{n}=3$; right panel). ${ }^{\mathrm{a}} \mathrm{P}<0.001$ vs. vehicle, ${ }^{\mathrm{P}}<0.05$ vs. $10 \mu \mathrm{M} \mathrm{UA},{ }^{\mathrm{P}}<0.001$ vs. $5 \mu \mathrm{M} \mathrm{CQ}$. (E) $\mathrm{H} 1975$ cells were pre-treated without or with $5 \mu \mathrm{M} \mathrm{CQ}$ for $1 \mathrm{~h}$, then incubated with UA at $15 \mu \mathrm{M}$ for $48 \mathrm{~h}$, whole cell lysates were subjected to western blot analysis with the indicated antibodies (left panel). Relative densitometric quantification of protein expression was performed and data are presented as the means $\pm \mathrm{SD}\left(\mathrm{n}=3\right.$; right panel). ${ }^{\mathrm{a}} \mathrm{P}<0.001$ vs. vehicle, ${ }^{\mathrm{b}} \mathrm{P}<0.01 \mathrm{vs}$. vehicle, ${ }^{\mathrm{c}} \mathrm{P}<0.001 \mathrm{vs}$. $15 \mu \mathrm{M}$ UA, ${ }^{\mathrm{d}} \mathrm{P}<0.001$ vs. $5 \mu \mathrm{M} \mathrm{CQ}$. (F) H1975 cells were pre-treated without or with $10 \mu \mathrm{M} \mathrm{LY} 294002$ for $1 \mathrm{~h}$, followed by UA treatment at $20 \mu \mathrm{M}$ for $24 \mathrm{~h}$. The cells were harvested and subjected to western blot analysis using the indicated antibodies (left panel). Relative densitometric quantification of protein expression was performed and data are presented as the means $\pm \mathrm{SD}\left(\mathrm{n}=3\right.$; right panel). ${ }^{\mathrm{a}} \mathrm{P}<0.001$ vs. vehicle, ${ }^{\mathrm{b}} \mathrm{P}<0.001$ vs. $20 \mu \mathrm{M}$ UA. UA, ursolic acid; $\mathrm{CQ}$, chloroquine; LY, LY294002.

of cytoplasmic LC3-I to the lapidated LC3-II that is generally used as a marker to monitor autophagy $(38,39)$. In the present study, western blot analysis revealed that UA markedly elevated the level of LC3-II in a concentration-dependent manner in the H460, H1975 and A549 cells (Fig. 3B). The distribution of endogenous LC 3 in the H460 and H1975 cells was also analyzed 
A

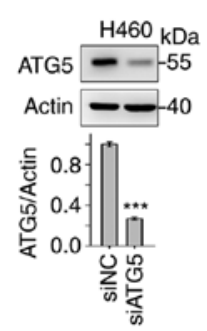

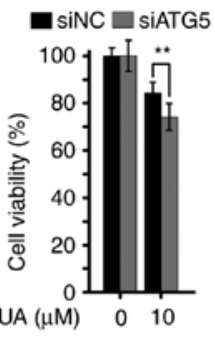

B

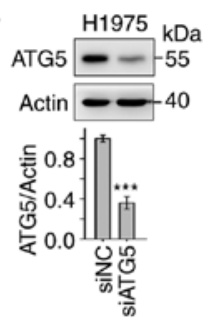

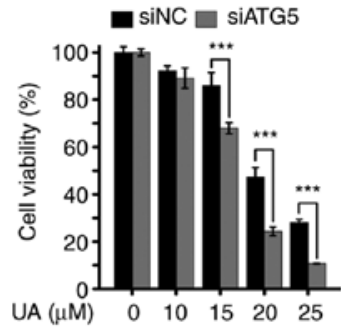

C

15

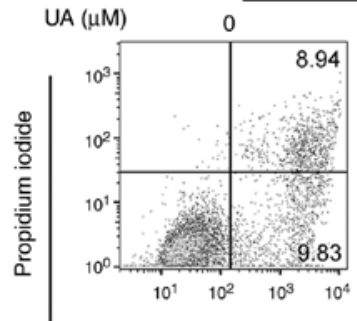

5

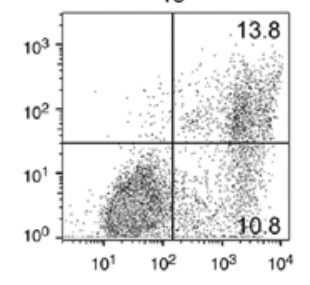

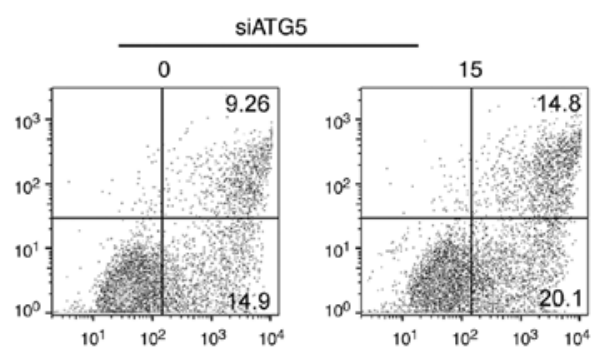

Annexin V-FITC

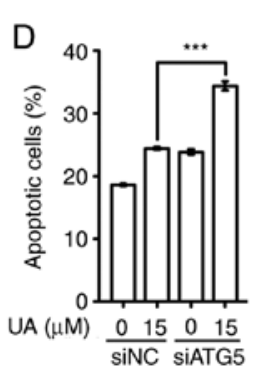

E<smiles>[CH-]CCC</smiles>
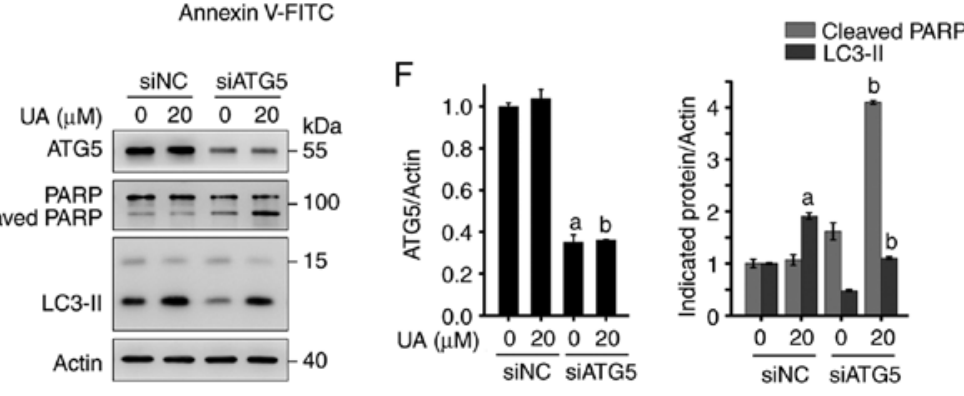

Figure 6. Autophagy inhibition by siRNA for ATG5 potentiates the UA-induced inhibition of the proliferation and promotes the UA-induced apoptosis of NSCLC cells. (A and B) H460 and H1975 cells were transfected with siNC or siATG5 for $36 \mathrm{~h}$, treated with the indicated concentrations of UA for 48 h, and cell viability was determined by MTS assay. ${ }^{* *} \mathrm{P}<0.01$ and ${ }^{* * *} \mathrm{P}<0.001$. The knockdown efficiency was determined by western blot analysis. Relative densitometric quantification of the ATG5 expression was performed and data are presented as the means \pm SD ( $n=3$ ). (C) H1975 cells were transfected with siNC or siATG5 for $36 \mathrm{~h}$, treated with the indicated concentrations of UA for $48 \mathrm{~h}$, and cell apoptosis was analyzed by flow cytometry using Annexin V-FITC/PI staining. Representative images are shown. (D) Quantification of flow cytometric analysis of apoptosis. ${ }^{* * *} \mathrm{P}<0.001$. (E) H1975 cells were transfected with siNC or siATG5 for $36 \mathrm{~h}$, then treated with $20 \mu \mathrm{M}$ UA for $24 \mathrm{~h}$. Whole cell lysates were subjected to western blot analysis using indicated antibodies. Actin was used as a loading control. (F) Relative densitometric quantification of protein expression was performed using bands in (E). Data are presented as the mean \pm SD (n=3). ${ }^{a} \mathrm{P}<0.001$ vs. siNC $0 \mu \mathrm{M} \mathrm{UA},{ }^{\mathrm{b}} \mathrm{P}<0.001$ vs. siNC $20 \mu \mathrm{M} \mathrm{UA}$.

by immunofluorescence assay. As shown in Fig. 3C, the amount of LC3 puncta, representative of autophagosomes, increased in the UA-treated cells, whereas the control group cells exhibited a diffuse distribution of LC3. ATG5 is involved in vesicle formation and the lipidation of LC3 and plays pivotal roles in the process of autophagy $(40,41)$. The present study demonstrated that the knockdown of ATG5 by siRNA reduced the UA-induced LC3-II accumulation in the H460 and H1975 cells (Fig. 3D). In addition, the autophagic flux was evaluated by analyzing the level of LC3-II in the presence of CQ, which inhibits late-stage autophagy by blocking the fusion of autophagosomes and lysosomes (39). In the H460, H1975 and A549 cells, the LC3-II levels were elevated upon combination treatment with UA and CQ compared to single treatment alone (Fig. 3E), indicating that UA promoted the autophagic flux in these cells. Taken together, these results demonstrate that UA induces autophagy and increases the autophagic flux in NSCLC cells.

UA-induced autophagy is attributed to the inhibition of the PI3K/Akt/mTOR signaling pathway. Since the mTOR signaling pathway is a main negative regulator of autophagy (42-44), the present study examined whether UA-induced autophagy is associated with the inhibition of this signaling pathway. As shown in Fig. 4A, UA treatment suppressed the phosphorylation of S6K (p-S6K T389) and 4E-BP1 (p-4E-BP1 S65), two of the most well-characterized downstream effector molecules of mTOR complex 1 (mTORC1) (43). UA also suppressed the phosphorylation of S6 (p-S6 S240/244), a substrate of S6K (Fig. 4A). These results indicated that UA suppressed mTORC1 signaling. mTOR forms two structurally and functionally distinct multi-protein complexes: The mTORC1 and mTORC2 (45). mTORC2 phosphorylates Akt on S473 (46). We examined the effects of UA on mTORC2 signaling and found that UA markedly decreased the phosphorylation of Akt (S473) in the tested cells (Fig. 4A), suggesting that UA inhibits mTORC2 signaling.

To further confirm the role of the mTOR signaling pathway in UA-induced autophagy, phosphatidylinositol 3-kinase (PI3K) inhibitor, LY294002 (47), and the mTOR activator, 3BDO (48), were employed. It was found that pre-treatment with LY294002 suppressed the phosphorylation of Akt (S473) (Fig. 4B), whereas 3BDO upregulated p-S6K (T389) (Fig. 4C). LY294002 and 3BDO evidently attenuated the UA-induced 
expression of LC3-II in the NSCLC cells (Fig. 4B and C), demonstrating that the PI3K/Akt/mTOR signaling pathway is involved in UA-induced autophagy. The ERK1/2 signaling pathway is another major regulator of autophagy $(28,49,50)$; Thus, the present study wished to determine whether ERK1/2 signaling plays a role in UA-induced autophagy. It was found that a selective inhibitor of ERK1/2, U0126, downregulated p-ERK and suppressed the UA-induced upregulation of p-ERK (Fig. 4D). Pre-treatment with U0126 did not affect the UA-induced expression of LC3-II (Fig. 4D), suggesting that ERK1/2 signaling is not involved in UA-induced autophagy.

Autophagy inhibition enhances the anti-NSCLC activity of UA. Whether cancer therapy-induced autophagy is a pro-survival response or an anticancer effect, remains controversial $(28,51)$. In the present study, to assess the role of UA-induced autophagy in its antitumor effect, the autophagy inhibitor, CQ, was used in cells treated with UA.MTS assay revealed that the suppression of the late autophagic process with CQ $(5 \mu \mathrm{M})$ significantly potentiated the UA-induced inhibition of the proliferation of the $\mathrm{H} 460$, H1975 and A549 cells (Fig. 5A). Moreover, Annexin V-FITC/PI double staining demonstrated that CQ markedly enhanced the UA-induced apoptosis of H460 and H1975 cells (Fig. 5B and C). Consistently, CQ potentiated the UA-induced downregulation of the anti-apoptotic protein, Bcl-2, in the $\mathrm{H} 460$ cells (Fig. 5D) and the UA-induced cleavage of PARP in H1975 cells (Fig. 5E). The blockage of the autophagosome formation by LY294002 $(10 \mu \mathrm{M})$ also enhanced the UA-induced cleavage of PARP in the H1975 cells (Fig. 5F). It was further demonstrated that the silencing of ATG5 by siRNA enhanced the UA-induced inhibition of the proliferation of $\mathrm{H} 460$ and $\mathrm{H} 1975$ cells (Fig. 6A and B). In addition, siATG5 potentiated the UA-induced apoptosis of H1975 cells (Fig. 6C and D). The silencing of ATG5 resulted in the accumulation of cleaved PARP in the UA-treated H1975 cells (Fig. 6E and F). Collectively, these results suggest that UA-induced autophagy plays a protective role in NSCLC cells, and the suppression of autophagy enhances the anti-NSCLC activity of UA.

\section{Discussion}

UA is a natural pentacyclic triterpenoid that possesses anticancer activities against a variety of cancers in vitro and in vivo $(17,18,22,24,26)$. For example, UA has been shown to significantly suppress xenograft tumor growth in a human lung cancer H1975 xenograft mouse model (24). UA exhibits a low toxicity in human normal lung epithelial BEAS-2B cells, and exerts minimal toxic effects on the kidney and liver tissues in mice (24). Furthermore, UA has recently been promoted to enter clinical trials to investigate its effects on insulin sensitivity (phase II study) and muscle function in human sarcopenia (phase II and III studies) $(52,53)$. However, the underlying anti-lung cancer mechanisms of UA are not yet fully understood. In the present study, it was demonstrated that UA inhibited the proliferation of various lung cancer cells, including the human NSCLC cells, H460, H1975, A549, H1299 and H520, the human SCLC cells H82 and H446, and murine LLC cells (Fig. 1). Of note, UA exerted inhibitory effects on gefitinib-resistant H1975 cells that bear EGFR-L858R/T790M mutations and on H460 cells with wild-type EGFR, as well as on the SCLC cells H82 and H446 that harbor TP53 and RB1 mutations (Fig. 1). These findings indicate that UA possesses therapeutic potential in both NSCLC and SCLC, which warrants further investigation.

Previous studies have demonstrated that UA induces autophagy in some types of cancer cells, such as prostate (54), cervical (55), breast (56), gliomas (33) and oral (34) cancer cells. In the present study, it was found that UA increased the expression level of LC3-II and induced autophagosome accumulation in NSCLC cells (Fig. 3). However, both the upregulation of LC3-II and increased autophagosome formation can act as autophagy inducers or autophagy inhibitors $(57,58)$, which can be distinguished by the knockdown of ATG proteins or treatment with CQ (58-60). The presents study demonstrated that the knockdown of ATG5 by siRNA reduced the UA-induced accumulation of LC3-II in H460 and H1975 cells (Fig. 3). The LC3-II levels further increased upon the combined use of UA and CQ (Fig. 3). These results demonstrated that UA-induced autophagy was ATG5-dependent, and the upregulation of LC3-II and increased autophagosome formation may be autophagy inducers in the cells.

Several signaling molecules, such as mTOR, PI3Ks and mitogen-activated protein kinases (MAPKs), have been shown to play a role in regulating autophagy $(31,61)$. The serine/threonine kinase mTOR plays central roles in a number of fundamental cell processes, and abnormalities in this signaling pathway have been implicated in cancers (62). The class I PI3K activates the downstream effector Akt, leading to activation of mTORC1 and inhibition of autophagy $(28,43)$. MAPKs, including ERK1/2, Jun $\mathrm{N}$-terminal kinase (JNK) and p38 MAPK, belong to the family of serine/threonine kinases that control a variety of cellular events, such as proliferation, apoptosis and autophagy (50). In the present study, it was identified that the inhibition of the $\mathrm{PI} 3 \mathrm{~K} / \mathrm{Akt} / \mathrm{mTOR}$ signaling pathway, rather than the activation of the ERK1/2 signaling pathway, was a mechanism of UA-induced autophagy in NSCLC cells (Fig. 4).

Increasing evidence implicates a dual role of autophagy in cancer therapy, i.e., protecting cell survival and promoting cell apoptosis $(51,63)$. It has been reported that the blocking of autophagy increases erianin or betulinic acid-induced apoptosis $(64,65)$. In the present study, it was found that the inhibition of autophagy by CQ or siATG5 enhanced the UA-induced inhibition of cell proliferation and promoted the UA-induced apoptosis (Figs. 5 and 6), indicating that UA-induced autophagy plays a pro-survival role in NSCLC cells; combined treatment with UA and autophagy inhibitor may have therapeutic potentials for this lethal disease. However, further investigations with multiple animal experiments are required prior to the clinical application of the present results.

\section{Acknowledgements}

Not applicable.

\section{Funding}

The present study was supported by the Key Project of the National Natural Science Foundation of China (81830093), the National Natural Science Funds for Distinguished Young Scholar (81425025), the CAMS Innovation Fund for Medical 
Sciences (CIFMS; 2019-I2M-1-003), and the National Natural Science Foundation of China (81672765, 81802796). The study sponsors had no role in the design of the study; the data collection, analysis, or interpretation; the writing of the article; or the decision to submit for publication.

\section{Availability of data and materials}

All data generated or analyzed during this study are included in this published article or are available from the corresponding author on reasonable request.

\section{Authors' contributions}

The project was conceived and designed by GBZ and MW. The experiments were conducted by MW, HY, RW, ZYC, QH, YFZ and SHG. Data were analyzed by GBZ and MW. The manuscript was written by GBZ and MW. All authors have read and approved the final manuscript.

\section{Ethics approval and consent to participate}

Not applicable.

\section{Patient consent for publication}

Not applicable.

\section{Competing interests}

The authors declare that they have no competing interests.

\section{References}

1. Bray F, Ferlay J, Soerjomataram I, Siegel RL, Torre LA and Jemal A: Global cancer statistics 2018: GLOBOCAN estimates of incidence and mortality worldwide for 36 cancers in 185 countries. CA Cancer J Clin 68: 394-424, 2018.

2. Herbst RS, Morgensztern D and Boshoff C: The biology and management of non-small cell lung cancer. Nature 553: 446-454 2018.

3. Hirsch FR, Scagliotti GV, Mulshine JL, Kwon R, Curran WJ Jr, Wu YL and Paz-Ares L: Lung cancer: Current therapies and new targeted treatments. Lancet 389: 299-311, 2017.

4. Ackermann CJ, Reck M, Paz-Ares L, Barlesi F and Califano R: First-line immune checkpoint blockade for advanced non-small-cell lung cancer: Travelling at the speed of light. Lung Cancer 134: 245-253, 2019.

5. Siegel RL, Miller KD and Jemal A: Cancer statistics, 2019. CA Cancer J Clin 69: 7-34, 2019.

6. Gazdar AF, Bunn PA and Minna JD: Small-cell lung cancer: What we know, what we need to know and the path forward. Nat Rev Cancer 17: 725-737, 2017.

7. Li JW and Vederas JC: Drug discovery and natural products: End of an era or an endless frontier? Science 325: 161-165, 2009.

8. Newman DJ and Cragg GM: Natural products as sources of new drugs from 1981 to 2014. J Nat Prod 79: 629-661, 2016.

9. Gordaliza M: Natural products as leads to anticancer drugs. Clin Transl Oncol 9: 767-776, 2007.

10. Boufridi A and Quinn RJ: Harnessing the properties of natural products. Annu Rev Pharmacol Toxicol 58: 451-470, 2018.

11. Harvey AL, Edrada-Ebel R and Quinn RJ: The re-emergence of natural products for drug discovery in the genomics era. Nat Rev Drug Discov 14: 111-129, 2015.

12. Luo J, Hu YL and Wang H: Ursolic acid inhibits breast cancer growth by inhibiting proliferation, inducing autophagy and apoptosis, and suppressing inflammatory responses via the $\mathrm{PI} 3 \mathrm{~K} / \mathrm{AKT}$ and NF- $\mathrm{KB}$ signaling pathways in vitro. Exp Ther Med 14: 3623-3631, 2017
13. Zhang Y, Huang L, Shi H, Chen H, Tao J, Shen R and Wang T: Ursolic acid enhances the therapeutic effects of oxaliplatin in colorectal cancer by inhibition of drug resistance. Cancer Sci 109: 94-102, 2018

14. Lu J, Wu DM, Zheng YL, Hu B, Zhang ZF, Ye Q, Liu CM, Shan Q and Wang YJ: Ursolic acid attenuates D-galactose-induced inflammatory response in mouse prefrontal cortex through inhibiting AGEs/RAGE/NF- $\kappa$ B pathway activation. Cereb Cortex 20: 2540-2548, 2010.

15. Kashyap D, Sharma A, Tuli HS, Punia S and Sharma AK: Ursolic acid and oleanolic acid: Pentacyclic Terpenoids with promising anti-inflammatory activities. Recent Pat Inflamm Allergy Drug Discov 10: 21-33, 2016.

16. Liobikas J, Majiene D, Trumbeckaite S, Kursvietiene L, Masteikova R, Kopustinskiene DM, Savickas A and Bernatoniene J: Uncoupling and antioxidant effects of ursolic acid in isolated rat heart mitochondria. J Nat Prod 74: 1640-1644, 2011.

17. Shanmugam MK, Manu KA, Ong TH, Ramachandran L, Surana R, Bist P, Lim LH, Kumar AP, Hui KM and Sethi G: Inhibition of CXCR4/CXCL12 signaling axis by ursolic acid leads to suppression of metastasis in transgenic adenocarcinoma of mouse prostate model. Int J Cancer 129: 1552-1563, 2011.

18. Yang LJ, Tang Q, Wu J, Chen Y, Zheng F, Dai Z and Hann SS: Inter-regulation of IGFBP1 and FOXO3a unveils novel mechanism in ursolic acid-inhibited growth of hepatocellular carcinoma cells. J Exp Clin Cancer Res 35: 59, 2016.

19. Senthil S, Chandramohan G and Pugalendi KV: Isomers (oleanolic and ursolic acids) differ in their protective effect against isoproterenol-induced myocardial ischemia in rats. Int J Cardiol 119: 131-133, 2007.

20. Raphael TJ and Kuttan G: Effect of naturally occurring triterpenoids ursolic acid and glycyrrhizic acid on the cell-mediated immune responses of metastatic tumor-bearing animals. Immunopharmacol Immunotoxicol 30: 243-255, 2008.

21. Jiménez-Arellanes A, Luna-Herrera J, Cornejo-Garrido J, López-García S, Castro-Mussot ME, Meckes-Fischer M, Mata-Espinosa D, Marquina B, Torres J and Hernández-Pando R: Ursolic and oleanolic acids as antimicrobial and immunomodulatory compounds for tuberculosis treatment. BMC Complement Altern Med 13: 258, 2013.

22. Mancha-Ramirez AM and Slaga TJ: Ursolic acid and chronic disease: An overview of UA's effects on prevention and treatment of obesity and cancer. Adv Exp Med Biol 928: 75-96, 2016.

23. Kashyap D, Tuli HS and Sharma AK: Ursolic acid (UA): A metabolite with promising therapeutic potential. Life Sci 146: 201-213, 2016.

24. Yang K, Chen Y, Zhou J, Ma L, Shan Y, Cheng X, Wang Y, Zhang Z, Ji X, Chen L, et al: Ursolic acid promotes apoptosis and mediates transcriptional suppression of CT45A2 gene expression in non-small-cell lung carcinoma harbouring EGFR T790M mutations. Br J Pharmacol 176: 4609-4624, 2019.

25. Chen CJ, Shih YL, Yeh MY, Liao NC, Chung HY, Liu KL, Lee MH, Chou PY, Hou HY, Chou JS and Chung JG: Ursolic acid induces apoptotic cell death through AIF and Endo G release through a mitochondria-dependent pathway in NCI-H292 human lung cancer cells in vitro. In Vivo 33: 383-391, 2019.

26. Xu CG, Zhu XL, Wang W and Zhou XJ: Ursolic acid inhibits epithelial-mesenchymal transition in vitro and in vivo. Pharm Biol 57: 169-175, 2019.

27. Huang CY, Lin CY, Tsai CW and Yin MC: Inhibition of cell proliferation, invasion and migration by ursolic acid in human lung cancer cell lines. Toxicol In Vitro 25: 1274-1280, 2011.

28. Kondo Y, Kanzawa T, Sawaya R and Kondo S: The role of autophagy in cancer development and response to therapy. Nat Rev Cancer 5: 726-734, 2005.

29. Chen Q, Kang J and Fu C: The independence of and associations among apoptosis, autophagy, and necrosis. Signal Transduct Target Ther 3: 18, 2018.

30. Maiuri MC, Zalckvar E, Kimchi A and Kroemer G: Self-eating and self-killing: Crosstalk between autophagy and apoptosis. Nat Rev Mol Cell Biol 8: 741-752, 2007.

31. Hasima N and Ozpolat B: Regulation of autophagy by polyphenolic compounds as a potential therapeutic strategy for cancer. Cell Death Dis 5: e1509, 2014.

32. Maes H, Rubio N, Garg AD and Agostinis P: Autophagy: Shaping the tumor microenvironment and therapeutic response. Trends Mol Med 19: 428-446, 2013.

33. Shen S, Zhang Y, Zhang R, Tu X and Gong X: Ursolic acid induces autophagy in U87MG cells via ROS-dependent endoplasmic reticulum stress. Chem Biol Interact 218: 28-41, 2014. 
34. Lin CW, Chin HK, Lee SL, Chiu CF, Chung JG, Lin ZY, Wu CY, Liu YC, Hsiao YT, Feng CH, et al: Ursolic acid induces apoptosis and autophagy in oral cancer cells. Environ Toxicol 34: 983-991, 2019.

35. Wang M, Zhou A, An T, Kong L, Yu C, Liu J, Xia C, Zhou H and Li Y: N-Hydroxyphthalimide exhibits antitumor activity by suppressing mTOR signaling pathway in BT-20 and LoVo cells. J Exp Clin Cancer Res 35: 41, 2016.

36. Tang ZH, Chen X, Wang ZY, Chai K, Wang YF, Xu XH, Wang XW, Lu JH, Wang YT, Chen XP and Lu JJ: Induction of $\mathrm{C} / \mathrm{EBP}$ homologous protein-mediated apoptosis and autophagy by licochalcone A in non-small cell lung cancer cells. Sci Rep 6: 26241, 2016

37. Pistritto G, Trisciuoglio D, Ceci C, Garufi A and D'Orazi G: Apoptosis as anticancer mechanism: Function and dysfunction of its modulators and targeted therapeutic strategies. Aging (Albany NY) 8: 603-619, 2016.

38. Kabeya Y, Mizushima N, Ueno T, Yamamoto A, Kirisako T, Noda T, Kominami E, Ohsumi Y and Yoshimori T: LC3, a mammalian homologue of yeast Apg8p, is localized in autophagosome membranes after processing. EMBO J 19: 5720-5728, 2000.

39. Janku F, McConkey DJ, Hong DS and Kurzrock R: Autophagy as a target for anticancer therapy. Nat Rev Clin Oncol 8: 528-539, 2011.

40. Luo S and Rubinsztein DC: Atg5 and Bcl-2 provide novel insights into the interplay between apoptosis and autophagy. Cell Death Differ 14: 1247-1250, 2007.

41. Mizushima N, Yoshimori T and Ohsumi Y: The role of Atg proteins in autophagosome formation. Annu Rev Cell Dev Biol 27: 107-132, 2011.

42. Fleming A, Noda T, Yoshimori T and Rubinsztein DC: Chemical modulators of autophagy as biological probes and potential therapeutics. Nat Chem Biol 7: 9-17, 2011.

43. Shimobayashi M and Hall MN: Making new contacts: The mTOR network in metabolism and signalling crosstalk. Nat Rev Mol Cell Biol 15: 155-162, 2014.

44. Munson MJ and Ganley IG: MTOR, PIK3C3, and autophagy: Signaling the beginning from the end. Autophagy 11: 2375-2376, 2015.

45. Zoncu R, Efeyan A and Sabatini DM: mTOR: From growth signal integration to cancer, diabetes and ageing. Nat Rev Mol Cell Biol 12: 21-35, 2011.

46. Sarbassov DD, Guertin DA, Ali SM and Sabatini DM: Phosphorylation and regulation of Akt/PKB by the rictor-mTOR complex. Science 307: 1098-1101, 2005.

47. Blommaart EF, Krause U, Schellens JP, Vreeling-Sindelárová $\mathrm{H}$ and Meijer AJ: The phosphatidylinositol 3-kinase inhibitors wortmannin and LY294002 inhibit autophagy in isolated rat hepatocytes. Eur J Biochem 243: 240-246, 1997.

48. Ge D, Han L, Huang S, Peng N, Wang P, Jiang Z, Zhao J, Su L, Zhang S, Zhang Y, et al: Identification of a novel MTOR activator and discovery of a competing endogenous RNA regulating autophagy in vascular endothelial cells. Autophagy 10: 957-971, 2014.

49. Aoki H, Takada Y, Kondo S, Sawaya R, Aggarwal BB and Kondo Y: Evidence that curcumin suppresses the growth of malignant gliomas in vitro and in vivo through induction of autophagy: Role of Akt and extracellular signal-regulated kinase signaling pathways. Mol Pharmacol 72: 29-39, 2007.
50. Cagnol S and Chambard JC: ERK and cell death: Mechanisms of ERK-induced cell death-apoptosis, autophagy and senescence. FEBS J 277: 2-21, 2010.

51. Wirawan E, Vanden Berghe T, Lippens S, Agostinis P and Vandenabeele P: Autophagy: For better or for worse. Cell Res 22: 43-61, 2012.

52. Li Y, Xing D, Chen Q and Chen WR: Enhancement of chemotherapeutic agent-induced apoptosis by inhibition of NF-kappaB using ursolic acid. Int J Cancer 127: 462-473, 2010.

53. Shan J, Xuan Y, Zhang Q, Zhu C, Liu Z and Zhang S: Ursolic acid synergistically enhances the therapeutic effects of oxaliplatin in colorectal cancer. Protein Cell 7: 571-585, 2016.

54. Shin SW, Kim SY and Park JW: Autophagy inhibition enhances ursolic acid-induced apoptosis in PC3 cells. Biochim Biophys Acta 1823: 451-457, 2012.

55. Leng S, Hao Y, Du D, Xie S, Hong L, Gu H, Zhu X, Zhang J, Fan D and Kung HF: Ursolic acid promotes cancer cell death by inducing Atg5-dependent autophagy. Int J Cancer 133: 2781-2790, 2013

56. Zhao C, Yin S, Dong Y, Guo X, Fan L, Ye M and $\mathrm{Hu} \mathrm{H}$ : Autophagy-dependent EIF2AK3 activation compromises ursolic acid-induced apoptosis through upregulation of MCL1 in MCF-7 human breast cancer cells. Autophagy 9: 196-207, 2013.

57. Mizushima N and Yoshimori T: How to interpret LC3 immunoblotting. Autophagy 3: 542-545, 2007.

58. Galluzzi L, Bravo-San Pedro JM, Levine B, Green DR and Kroemer G: Pharmacological modulation of autophagy: Therapeutic potential and persisting obstacles. Nat Rev Drug Discov 16: 487-511, 2017

59. Wiedmer T, Blank A, Pantasis S, Normand L, Bill R, Krebs P, Tschan MP, Marinoni I and Perren A: Autophagy inhibition improves sunitinib efficacy in pancreatic neuroendocrine tumors via a lysosome-dependent mechanism. Mol Cancer Ther 16: 2502-2515, 2017.

60. Zhang L, Qiang P, Yu J, Miao Y, Chen Z, Qu J, Zhao Q, Chen Z, Liu Y, Yao X, et al: Identification of compound CA-5f as a novel late-stage autophagy inhibitor with potent anti-tumor effect against non-small cell lung cancer. Autophagy 15: 391-406, 2019.

61. Deng S, Shanmugam MK, Kumar AP, Yap CT, Sethi G and Bishayee A: Targeting autophagy using natural compounds for cancer prevention and therapy. Cancer 125: 1228-1246, 2019.

62. Saxton RA and Sabatini DM: mTOR signaling in growth, metabolism, and disease. Cell 169: 361-371, 2017.

63. Wu WK, Coffelt SB, Cho CH, Wang XJ, Lee CW, Chan FK, $\mathrm{Yu} \mathrm{J}$ and Sung JJ: The autophagic paradox in cancer therapy. Oncogene 31: 939-953, 2012.

64. Wang H, Zhang T, Sun W, Wang Z, Zuo D, Zhou Z, Li S, Xu J, Yin F, Hua Y and Cai Z: Erianin induces G2/M-phase arrest, apoptosis, and autophagy via the ROS/JNK signaling pathway in human osteosarcoma cells in vitro and in vivo. Cell Death Dis 7 : e2247, 2016.

65. Wang S, Wang K, Zhang C, Zhang W, Xu Q, Wang Y, Zhang Y, Li Y, Zhang Y, Zhu H, et al: Overaccumulation of p53-mediated autophagy protects against betulinic acid-induced apoptotic cell death in colorectal cancer cells. Cell Death Dis 8: e3087, 2017.

(i) (3) This work is licensed under a Creative Commons cc) $\mathrm{EY}$ NO NO Attribution-NonCommercial-NoDerivatives 4.0 International (CC BY-NC-ND 4.0) License. 